\section{Gategory}

Metal-Catalyzed Asymmetric

Synthesis and

Stereoselective

Reactions

\section{Key words}

asymmetric

catalysis

hydroxymethylation

reductive coupling

paraformaldehyde

allylic acetates

iridium

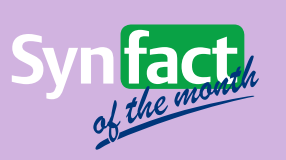

V. J. GARZA, M. J. KRISCHE* (UNIVERSITY OF TEXAS AT AUSTIN, USA)

Hydroxymethylation beyond Carbonylation: Enantioselective Iridium-Catalyzed Reductive Coupling of Formaldehyde with Allylic Acetates via Enantiotopic $\pi$-Facial Discrimination

J. Am. Chem. Soc. 2016, 138, 3655-3658.

\title{
Iridium-Catalyzed Asymmetric Hydroxymethylation
}

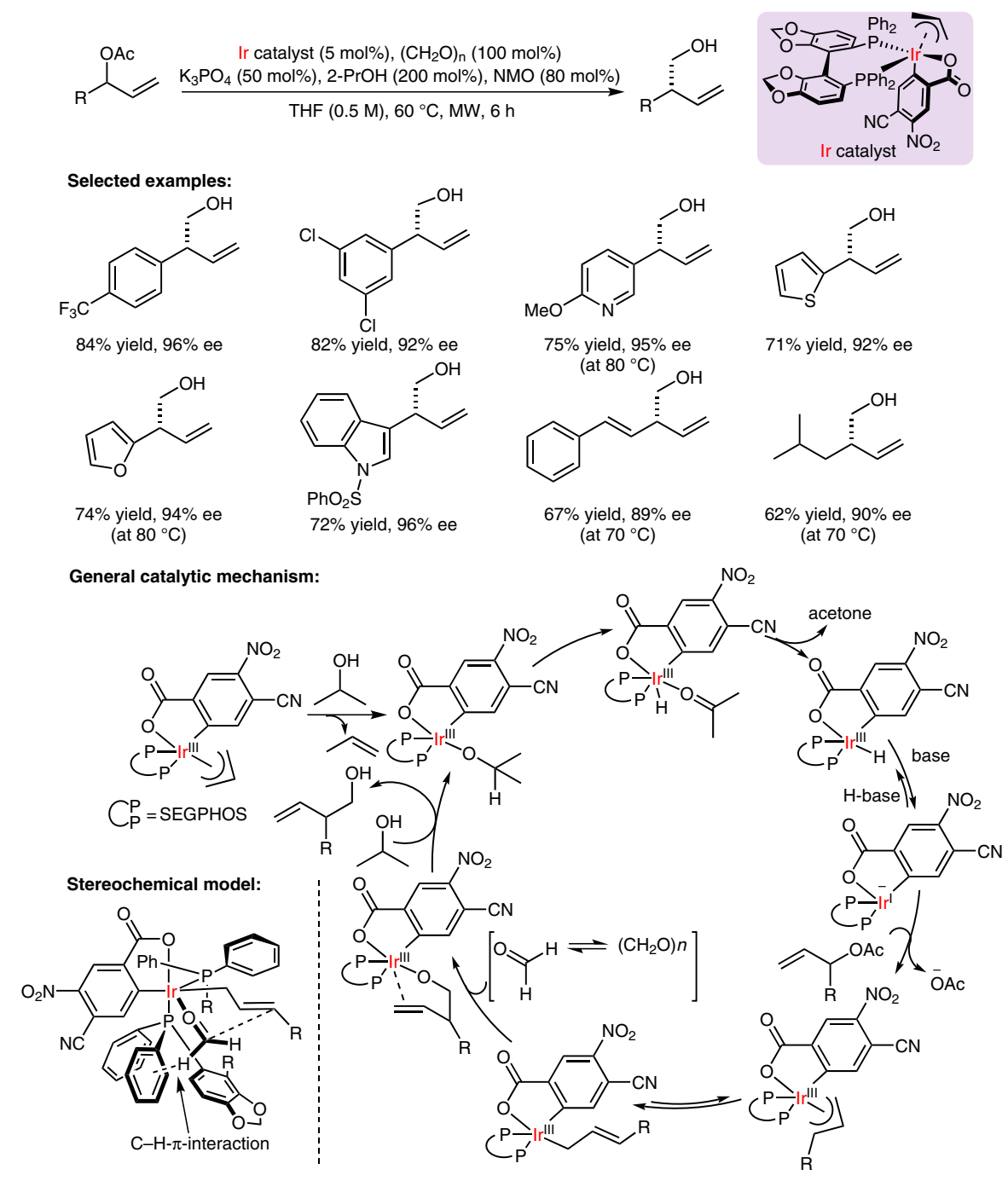

Significance: Existing examples of enantioselective $\mathrm{C}-\mathrm{C}$ coupling reactions of formaldehyde involve asymmetric aldol reactions. Krische and Garza describe the first asymmetric nucleophilic allylation of formaldehyde in the presence of iridium catalysts to give chiral $\beta$-stereogenic primary homoallylic alcohols.
Comment: The chiral iridium complex modified by SEGPHOS permits propan-2-ol-mediated regioand enantioselective reductive coupling of branched allylic acetates with paraformaldehyde. The reaction proceeds through formation of an iridium hydride and subsequent formation of $\pi$-allyliridium intermediates.

SYNFACTS Contributors: Hisashi Yamamoto, Sukalyan Bhadra DOI: 10.1055/s-0035-1562065; Reg-No.: H03416SF 